\title{
Analysis of Characteristics of Road Traffic Accident Casualties in Guilin
}

\author{
Wenyu Qin, Xiang Liu, Zhibin Kong* \\ Department of Emergency, The 181st Hospital of PLA, Guilin, China \\ Email: *kongzb181@163.com
}

How to cite this paper: Qin, W.Y., Liu, X. and Kong, Z.B. (2018) Analysis of Characteristics of Road Traffic Accident Casualties in Guilin. Open Journal of Social Sciences, 6, 90-96.

https://doi.org/10.4236/jss.2018.66009

Received: April 24, 2018

Accepted: June 8, 2018

Published: June 11, 2018

Copyright $\odot 2018$ by authors and Scientific Research Publishing Inc. This work is licensed under the Creative Commons Attribution International License (CC BY 4.0).

http://creativecommons.org/licenses/by/4.0/

\begin{abstract}
Objectives: To explore the characteristics of road traffic accident casualties and time distribution characteristics of road traffic crashes in Guilin. Methods: We analyzed the data of road traffic crashes in 2007-2014 of Guilin to explore the casualty's features of road traffic injuries and time distribution characteristics of road traffic crashes. Results: A total of 3162 road traffic accident casualties were studied. The majority of the study subjects were males (63.23\%) who suffered almost twice as females. The casualties' ages ranged from 5 to 78 years with the mean age $33.65 \pm 16.76$ years. The mortality rate of RTCs was significantly higher in males than in females (61.39 versus 38.61 , $\mathrm{P}<0.05)$. RTIs disproportionately affected adult people, with the majority of those fatalities occurred among people aged 15 - 59 years. The mortality rates of RTCs varied greatly by educational status, more than one-third occurred in people of secondary school. Approximately $40.25 \%$ of fatalities of road traffic crashes occurred in daily laborer showed that mortality rate was significantly higher than other occupations $(\mathrm{P}<0.05)$. The distribution of season from road traffic deaths involved Spring (24.72\%), Summer (15.56\%), Autumn (30.56\%), and Winter (29.17\%). The proportion of road traffic deaths varied from the lowest $6.02 \%$ in 9:00 - 12:00 to the highest $16.78 \%$ in 0:00 - 3:0; midnight (0:00 - 3:00) shows a significantly higher proportion of reported road traffic deaths $(\mathrm{P}<0.05)$. The upper limbs and lower limbs were the most common body region injured accounting for $16.57 \%$ and $17.84 \%$ of cases respectively; the highest fatality rate of head was $20.77 \%$ and followed by abdomen of $15.75 \%$. Conclusions: This study showed diverse morbidity and mortality characteristics among the casualties and varied the road traffic accident rate and fatality rate from season and time. Corresponding measures to reduce the occurrence of traffic injuries should be formulated according to different population and time.
\end{abstract}

\section{Keywords}

Road Traffic Crashes, Road Traffic Injuries, Injury Characteristics 


\section{Introduction}

According to The Global Status Report on Road Safety 2015 from the World Health Organization (WHO), more than 1.25 million people each year die of roads traffic crashes (RTCs) in the whole world, which means that over 3400 people die on the world's RTCs every day [1]. Road traffic injuries (RTIs) are the leading cause of death and disability among young people aged 15 - 29, which have a huge impact on the family and entire society in low-income, middle-income, and high-income countries [1] [2] [3]. WHO estimates that RTIs will become the fifth leading cause of death worldwide by 2030 if without effective measures [1]. In the wake of the developing of economy and technology, China is undergoing rapid motorization with a mixture of motorized vehicles including cars, trucks and more motorcycles. In recent years the mortality of RTIs in China was steadily increased and has become one of the biggest problems in the public health area [3] [4]. Poor knowledge of local road conditions and a lack of understanding of local traffic rules may result in increasing risks of traffic crash involvement. Road safety has a profound impact on health and economy; preventing RTCs and reducing casualties is a social problem of public concern. RTCs not only threaten the health of life and hurt the feelings of relatives, but also bring an extremely heavy economic burden to them. The global economic losses caused by traffic crashes are as high as $\$ 518$ billion per year [1]. Guilin locates in north of Guangxi providence, which is an international tourist city with unique landscape resources and profound historical culture. Its road traffic crashes occur frequently due to its special geographical location, which is small, mountainous and densely inhabited and with narrow and crowded roads. The purpose of this study is to analyze the characteristics of RTCs casualties in Guilin to explore its related factors and to provide a basis for the development of corresponding countermeasures to further reduce the casualties.

\section{Data and Methods}

\subsection{Data Source}

The traffic crash data from 2007 to 2014 was provided by the traffic police brigade of various districts of Guilin.

\subsection{Data Analysis}

Rates and proportions were the main indexes of the study. Age was divided into seven groups $(0-14,15$ - 24, 25 - 34, 35 - 44, 45 - 54, 55 - 64, and $>65$ years) for comparison purposes. The proportion of road traffic crash fatalities was compared by hour of day and season of year. Time of crash is defined using variables with eight groups (0:00 - 3:00, 3:00 - 6:00, 6:00 - 9:00, 9:00 - 12:00, 12:00 - 15:00, 15:00 - 18:00, and 18:00 - 21:00, 21:00 - 24:00). Season of RTCs was defined four variables: Spring (March-May), Summer (June-August), Autumn (September-November), and Winter (January, February and December). Comparisons between the rates of variables were done using chi-squared test and measure- 
ment data using $\mathrm{T}$ tests. All statistical analyses were performed using the statistical package for social sciences for windows (SPSS19.0) $\mathrm{P} \leq 0.05$ were considered statistically significant.

\section{Results}

The crash and victim-related information of the total RTCs are given in Table 1 and Table 2. A total of 3162 individuals suffered road traffic crashes, 2802 person injured and $360(11.39 \%)$ person died from RTCs throughout the period 2007-2014, but males who suffered almost twice as females did accounts for the percentage of $63.24 \%$. The casualties' ages ranged from 5 to 78 years with the mean age $33.65 \pm 16.76$ years. Casualties' characteristics of RTCs by gender, age, educational status and occupation are presented in Table 1 . The mortality rate of RTCs was significantly higher in males than in females (61.39 versus 38.61, $\mathrm{P}$ $<0.05)$. RTIs disproportionately affected adult people, with the majority of those fatalities occurred among people aged 15 - 59 years, aged 15 - 29 years accounted

Table 1. The outline of casualty of road traffic accident.

\begin{tabular}{|c|c|c|c|c|}
\hline Variables & Total (\%) & Dead (\%) & Injured (\%) & P-value \\
\hline Total & 3162 & 360 & 2802 & \\
\hline Gender & & & & 0.015 \\
\hline Male & 63.24 & 61.39 & 64.17 & \\
\hline Female & 36.76 & 38.61 & 35.83 & \\
\hline Age & & & & 0.021 \\
\hline $0-14$ & 6.9 & 7.1 & 7.5 & \\
\hline $15-29$ & 23.67 & 29.12 & 32.14 & \\
\hline $30-44$ & 31.11 & 28.04 & 25.23 & \\
\hline $45-59$ & 29.16 & 20.22 & 21.38 & \\
\hline$\geq 60$ & 9.16 & 15.52 & 13.75 & \\
\hline Educational status & & & & 0.034 \\
\hline Cannot read and write & 7.53 & 6.76 & 7.28 & \\
\hline Can read and write & 16.37 & 15.83 & 16.58 & \\
\hline Primary school & 26.29 & 24.68 & 25.97 & \\
\hline Secondary school & 33.86 & 34.74 & 33.28 & \\
\hline Higher school & 15.95 & 17.99 & 16.89 & \\
\hline Occupation & & & & 0.026 \\
\hline Student or trainee & 15.83 & 14.63 & 14.52 & \\
\hline Daily laborer & 40.25 & 41.37 & 42.45 & \\
\hline Businessman(merchant) & 9.69 & 8.79 & 9.19 & \\
\hline Famer & 8.83 & 8.98 & 7.26 & \\
\hline House wife & 6.97 & 5.49 & 4.75 & \\
\hline Car driver & 10.89 & 11.78 & 12.15 & \\
\hline Others & 7.54 & 8.96 & 9.68 & \\
\hline
\end{tabular}


Table 2. The time distribution of casualty of road traffic accident.

\begin{tabular}{ccccc}
\hline Variables & Total (\%) & Dead (\%) & Injured (\%) & P-value \\
\hline Seasons & & & & 0.037 \\
Spring & 25.72 & 24.72 & 31.37 & \\
Summer & 21.69 & 15.56 & 19.66 & \\
Autumn & 19.73 & 30.56 & 18.67 & \\
Winter & 32.87 & 29.17 & 30.3 & 0.022 \\
Time & & & & \\
0:00 - 3:00 & 9.77 & 16.78 & 11.01 & \\
3:00 - 6:00 & 6.36 & 10.89 & 8.29 & \\
6:00 - 9:00 & 20.75 & 14.96 & 18.1 & \\
9:00 - 12:00 & 6.96 & 6.02 & 8.13 & \\
$12: 00-15: 00$ & 17.51 & 15.45 & 14.75 & \\
$15: 00-18: 00$ & 11.83 & 11.01 & 12.47 & \\
$18: 00-21: 00$ & 19.17 & 16.34 & 18.26 & \\
21:00 - 24:00 & 7.65 & 8.55 & 8.99 & \\
\hline
\end{tabular}

for $29.12 \%$, and adults aged 30 - 44 years approximately $28.04 \%$ of total road traffic deaths, 0 - 14 year-old age group was the lowest among all age groups. Regarding educational status of road traffic accident victim, the mortality rates of RTCs varied greatly by educational status, more than one-third occurred in people of secondary school. Accounting for $26.29 \%$ of them had attended a primary school education while $15.95 \%$ of the casualties had reported higher educational level education. The numbers of road traffic deaths varied by occupation. Approximately $40.25 \%$ of fatalities of road traffic crashes occurred in daily laborer, followed by students or trainee (15.83\%) and $10.89 \%$ occurred in car driver. Comparing mortality rate of occupation showed that mortality rate in daily laborer was significantly higher than others $(\mathrm{P}<0.05)$. Table 2 presents time distribution of fatalities from RTCs by season of year and hour of day. Of all road traffic deaths in 2007-2014, the distribution of season from road traffic deaths involved Spring (24.72\%), Summer (15.56\%), Autumn (30.56\%), and Winter (29.17\%). In all hours of day, the proportion of road traffic deaths varied from the lowest $6.02 \%$ in 9:00 - 12:00 to the highest $16.78 \%$ in 0:00 - 3:00, midnight $(0: 00-3: 00)$ show a significantly higher proportion of reported road traffic deaths $(\mathrm{P}<0.05)$. The upper limbs and lower limbs were the most common body region injured accounting for $16.57 \%$ and $17.84 \%$ of cases respectively, The fatality rate of head were $20.77 \%$ and followed by abdomen of $15.75 \%$, thoracic injuries were $13.68 \%$ of the road traffic accident casualties, as shown in Figure 1.

\section{Discussion}

According to the prediction of the WHO, injuries will be responsible for even more morbidity, mortality and disability, with significant socioeconomic impact 


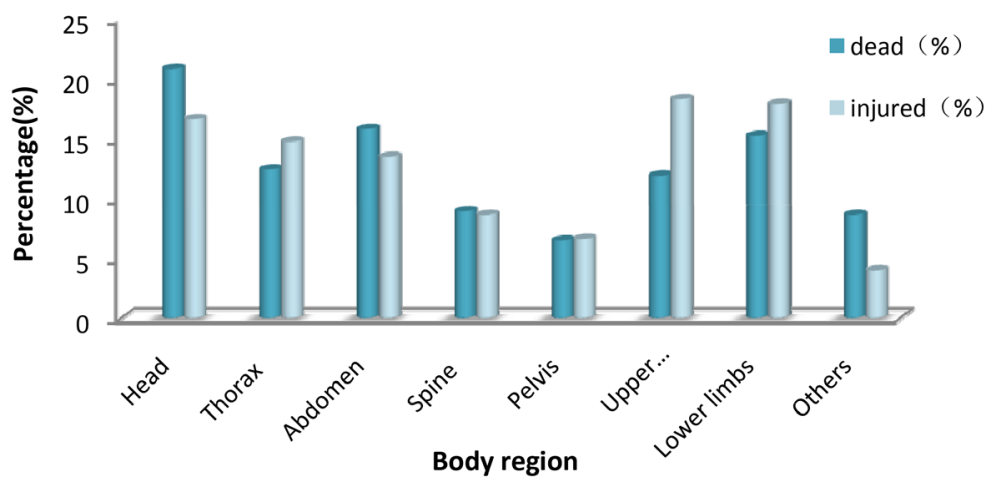

Figure 1. Body region of casualty.

on the developing countries [1]. China is a developing country with the largest population all over the world. The rapid economic growth has been accompanied by substantial changes, such as modes of transport and lifestyle, which result in some unfavorable and unexpected problems; and the deaths caused by RTIs have a serious impact on the families and communities, where life is often irrevocable under the influence of these tragedies [5] [6]. Injuries are an additional public health threat in China, causing at least 0.8 million deaths and 50 million non-fatal damages each year, of which 2.3 million cases result in disability with varying degrees of severity [7] [8]; preventing and reducing the occurrence of RTCs is a social problem of national concern. Accordingly, it is essential to well know the characteristic of RTCs and related factors.

The characteristic of RTCs varied from districts to districts, in addition, scene light, weather condition, place of crash, roadway defect, roadway geometrics and roadway surface were significantly associated with type of crash [9] [10] [11]. This study investigated the injury deaths in China from 2007 to 2014 and trends in injury mortality rates and related casualties by the criteria of gender, age and occupation and so on. The results showed that about $11.39 \%$ death resulting from injury-related causes, and $61.39 \%$ occurred in males who suffered almost twice as females. RTIs disproportionately affected adult people, with the majority of those fatalities occurred among people aged 15 - 59, specially aged $15-29$ accounted for the largest percentage of total road traffic deaths, which was in accordance with previous studies that injury is also the leading cause of death in China from age 15 - 29, which may be more outgoing activities and prefer driving fast and so on. Regarding educational status of road traffic accident victim, the mortality rates of RTCs varied greatly by educational status and most RTIs occurred in people of secondary school. Maybe these have something to do with traffic safety awareness. The numbers of road traffic deaths varied by occupation and approximately $40.25 \%$ of fatalities occurred in daily laborer that likely related with the exposure of road. Therefore, traffic safety awareness education and protection is essential for different population characteristics. Time distribution of fatalities from RTCs by season of year and hour of day, the distribution 
of season from road traffic deaths most happened in Autumn. Most likely some factors should be taking for consideration. Firstly, the fluctuation of travelers in various seasons based on the habitants in Guilin, that may be most largely one in Autumn. Secondly, due to the good weather that may be less traffic safety consciousness and speeding and so on. In all hours of day, the proportion of road traffic deaths varied, midnight (0:00 - 3:00) show a significantly higher proportion of reported road traffic deaths and it means that crash was more dangerous at midnight.The upper limbs and lower limbs were the most common body region injured but the highest of the fatality rate were head and followed by abdomen of casualties of RTCs.

Guilin lies on the south of the Xianggui corridor and adjacent to the important economic sectors in the Beibu gulf, is an important hub to connecting coastal and inland. With the rapid of economic developing, the speed of road and infrastructure construction has also been improved, while the number of motor vehicles has increased greatly. In this study, the youths and middle-aged people, especially the daily laborer accounted for the majority of RTCs that happened with different frequency in various seasons of a year and time of a day, and the most frequently wounded location was the limbs which were not the highest dead rate but the head. Thus it is imperative to build the establishment of RTCs prevention measures in accordance with the characteristic of RTCs. For example, measures that have raised the preventability of RTIs, taken appropriate measures while speeding up the road traffic hardware conditions, promoted good practice related to coping with behavior risk factors, reducing distracted driving, reducing speed, reducing drink-driving, increasing the use of motorcycle helmets and so on. We intend to further strengthen the safety education of road traffic participants and improve the medical treatment system, which make use of the existing medical network, expand the scope of first aid and enrich first aid medical personnel to improve the delivery mechanism, which aim to providing scientific evidences for the strategic policies and suggestions to restrain injury deaths for preventing of RTCs and death incidences of RTIs. As long as the factors that affect RTCs are deeply learned for thorough research, and law of RTCs for the prevention of RTCs and RTIs with a far-reaching impact on health and economy [12] [13] [14], which are the key to reduce the death rate of RTCs and the economic burden of diseases.

\section{Funding}

This study is a part of the fund project deriving from the Science and Technology Project of Guilin

\section{References}

[1] World Health Organisation (WHO) (2015) Global Status Report on Road Safety 2015. http://www.who.int

[2] Hamzeh, B., Najafi, F., Karamimatin, B., Ahmadijouybari, T., Salari, A. and Moradinazar, M. (2016) Epidemiology of Traffic Crash Mortality in West of Iran in a 9 
Year Period. Chinese Journal of Traumatology, 19, 70-74.

https://doi.org/10.1016/j.cjtee.2015.12.007

[3] Masoumi, K., Forouzan, A., Barzegari, H., et al. (2016) Effective Factors in Severity of Traffic Accident-Related Traumas: An Epidemiologic Study Based on the Haddon Matrix. Emergency, 4, 78-82.

[4] Yu, W., Chen, H., Lv, Y., Deng, Q., Kang, P. and Zhang, L. (2017) Comparison of Influencing Factors on Outcomes of Single and Multiple Road Traffic Injuries: A Regional Study in Shanghai, China (2011-2014). PLoS One, 12, 0176907. https://doi.org/10.1371/journal.pone.0176907

[5] Jiang, B.G. (2011) Status of Road Traffic Injury Rescue and Current Work in China. Chinese Medical Journal, 124, 3850-3851.

[6] Zhao, H., Yin, Z., Xiang, H., Liao, Z. and Wang, Z. (2017) Preliminary Study on Alterations of Altitude Road Traffic in China from 2006 to 2013. PLoS One, 12, 1-12.

[7] Chang, F., Li, M., Xu, P., Zhou, H., Haque, M.M. and Huang, H. (2016) Injury Severity of Motorcycle Riders Involved in Traffic Crashes in Hunan, China: A Mixed Ordered Logit Approach. International Journal of Environmental Research and Public Health, 13, 1-15. https://doi.org/10.3390/ijerph13070714

[8] Zhang, X., Yao, H., Hu, G., Cui, M. and Gu, Y. (2013) Basic Characteristics of Road Traffic Deaths in China. Iranian Journal of Public Health, 42, 7-15.

[9] Kong, Z.B., Liu, X. and Qin, W.Y. (2018) Analysis on Causes and Distribution Characteristic of Road Traffic Crashes in Guilin. Chinese Journal of Social Medicine, 35, 42-45.

[10] Huang, K.Y., Wang, X.M., et al. (2012) Traffic Environmental Factors for Road Traffic Injury in Guilin City. Chinese Journal of Public Health, 28, 571-573.

[11] Zhang, S., Xiong, X.Y., et al. (2010) Study on the Distribution of Traffic Accident in a Certain District of Chongqing. Journal of Trauma and Acute Care Surgery, 12, 52-55.

[12] Zhao, A., Chen, R., Qi, Y., et al. (2016) Evaluating the Impact of Criminalizing Drunk Driving on Road-Traffic Injuries in Guangzhou, China: A Time-Series Study. Journal of Epidemiology and Community Health, 26, 433-439. https://doi.org/10.2188/jea.JE20140103

[13] Pan, R.H., Chang, N.T., Chu, D., et al. (2014) Epidemiology of Orthopedic Fractures and Other Injuries among Inpatients Admitted Due to Traffic Accidents: A 10-Year Nationwide Survey in Taiwan. Scientific World Journal, 2014, Article ID: 637872. https://doi.org/10.1155/2014/637872

[14] Brand, S. (2012) Injury Patterns of Seniors in Traffic Accidents: A Technical and Medical Analysis. World Journal of Orthopedics, 3, 151.

https://doi.org/10.5312/wjo.v3.i9.151 